\title{
The relation between the cancer screening rate and the cancer mortality rate in Japan
}

\author{
Midori Yoshida, ${ }^{1,3)}$, Kazuya Kondo ${ }^{27}$, and Toshiko Tada" \\ ${ }^{1)}$ Department of Community Nursing, Major in Nursing, ${ }^{2}$ Department of Adult and Gerontological \\ Nursing, Major in Nursing, and ${ }^{3)}$ Department of Oral and Maxillofacial Radiology, Institute of Health \\ Biosciences, the University of Tokushima Graduate School, Tokushima, Japan
}

\begin{abstract}
The aim of this research was to clarify the relation between the screening rates for five cancers (lung cancer, stomach cancer, colorectal cancer, uterus cancer, and breast cancer) and their mortality rate by using publicly accessible databases. The used information materials were those prepared by the Ministry of Health, Labour and Welfare, the Center for Cancer Control and Information Services, and the National Cancer Center. Our results were as follows : 1) regarding stomach and colorectal cancers, a positive correlation was found between the screening rate and the mortality rate $(p<0.001) ; 2)$ in the relation between the screening rate and the mortality rate according to administrative divisions, the mortality rate decreased significantly when the lung cancer screening rate improved $(p<0.005) ; 3)$ the mortality rate for breast cancer increased in those aged 50 or over ; 4) the mortality rate for uterus cancer had been slightly increasing since 1990 ; and 5) regarding the screening rate, a positive correlation was found between breast cancer and uterus cancer $(\mathbf{p}<0.001)$. In future, improvement in lifestyle and in the knowledge of cancer should be promoted to enhance the screening rates. J. Med. Invest. 57 : 251-259, August, 2010
\end{abstract}

Keywords : stomach cancer, colorectal cancer, lung cancer, breast cancer, uterus cancer

\section{INTRODUCTION}

Cancers have been the greatest death cause in Japan since 1981. In 2008, they accounted for 340,000 of the total death number of 1.14 millions, reaching $30.0 \%$ of this total number (1). The history of the actions against cancers in Japan started from the establishment of a NPO "Japanese Foundation for Cancer Research" in 1908 with the aim of "Contributing the welfare of humankind by eradicating cancers" (2). In August 1958, proposed by Japanese

Received for publication March 24, 2010 ; accepted May 17, 2010.

Address correspondence and reprint requests to Midori Yoshida, Department of Oral and Maxillofacial Radiology, Institute of Health Biosciences, the University of Tokushima Graduate School, 3-18-15 Kuramoto-cho, Tokushima 770-8504, Japan and Fax : +81-88-633-5335.
Cancer Association, the Japan Cancer Society was established (3). In 1962, as a national policy, the National Cancer Center was established to play a core role in actions against cancers (4).

In every 10 years, the government sets out plans such as "Comprehensive 10-year Strategy for Cancer Control" operative since 1984 and "New 10-year Strategy to Overcome Cancer" since 1994. Since 2004, it has advanced "The 3rd-term Comprehensive 10-year Strategy for Cancer Control" (until 2013) containing the objectives of "Promotion of cancer prevention" and "Improvement of cancer treatment and of social environment to support this goal" as pillars. This aims to promote cancer research and to disseminate high quality cancer medical services with the slogan "Drastic reduction in cancer morbidity and mortality". 
As shown, measures against cancers have been gradually put into effect. Subsequently, for the sake of early detection of cancer, the Cancer Control Act 2007 was enacted to aim the screening rate of $50 \%$ within 5 years, and the implementation of accuracy management and project evaluation in all the municipalities. Additionally, the Ministry of Health, Labour and Welfare (MHLW) set "the Headquarters of 50\% Cancer Screening Rate" in 2009, showing its serious actions towards improvement in cancer screening rate (5).

Precedent studies on stomach cancer screening in Japan include a report suggesting that improving trends in the survival rate can be explained by early cancer detection although the effectiveness of screening is not proved yet $(6,7)$. From guidelines available in Japan $(8,9)$, as methods using photofluorography are recommended in population-based screening and opportunistic screening, early detection by and contents of screening are important.

Evidence for preventive measures to reduce the cancer mortality rate is available only in the aspect of the actions against smoking and some other cancer screenings (10). Cancer screening is considered to be very effective in reducing the cancer mortality rate as it enables cancer detection at an early stage of cancer development. Today, the following screenings are considered to be effective based on medical evidence : stomach cancer screening ; lung cancer screening ; colorectal cancer screening ; uterus cancer screening ; and breast cancer screening $(8,9,11)$. Thus, in this paper, the five mentioned cancer screenings are the subjects in order to examine the relation between the screening rate and the mortality rate on the basis of currently available information.

\section{MATERIALS AND METHODS}

The data on the screening rates and mortality rates were collected from databases and publications of the MHLW, the Center for Cancer Control and Information Services, the National Cancer Center, and the Cabinet Office $(5,12-15)$. In Japan, although the screening for uterus cancer targets those over 20 years old, the screenings for stomach cancer, lung cancer, colorectal cancer, and breast cancer target those over 40 . Hence, age groups over 40 were the subjects in this analysis.

On the screening rates, each of the cancer screenings started at a different period of time from each other. As there had possibly existed no established screening system at an early period, data from last 15 years (between 1993 and 2007) were analyzed. Also, as not all gender data on the screening rates were publicly open, the calculation of the rates was based on the values which were figured out from inferred screening rates according to gender from the gender ratios in the screening rates in 2007.

On the mortality rates, the data from 1958 to 2008 , and the crude mortality rates in the population of 100,000 (the number of cancer death divided by the population of the subject group) were used. The mortality rate for uterus cancer in women aged 20 or over, and the mortality rate for breast cancer in women aged 40 or over were re-calculated.

The classification based on the International Classification Diseases codes (ICD) was applied to the subject sites. The classification conformed to ICD7 for the data between 1958 and 1967, ICD- 8 between 1968 and 1976, ICD-9 between 1977 and 1994, and ICD-10 between 1995 and 2008. For stomach, code 151 (ICD-7, 8, 9) or code C16 (ICD10) was used. For lung, code 162-163 (ICD-7), code 162 (ICD-8, 9), or code C33-34 (ICD-10) was/were used. For colon, code 153-154 (ICD-7, 8, 9) or code C18-21 (ICD-10) were used ; for breast, code 170 (ICD-7), code 174 (ICD-7, 8), code 174-175, 233.0 (ICD-9), or code C50 D05 (ICD-10) was/were used. For uterus, code 171-174 (ICD - 7), code 180-182 (ICD-8), code 179-182 (ICD-9), or code C53-C55 (ICD-10) were used.

The relation between the mortality rate and the screening rate was examined by referring to the national level of the rates and the level according to administrative divisions. Data were used to analyze the national level in 15 years. However, because the cancer screening rate according to administrative divisions was published only until 2007, the screening rates and age-adjusted cancer death rates in 2007 were used in the analysis regarding administrative divisions. Linear regression analysis and regression coefficients were calculated in order to examine the relations between these variables. The statistics software of SPSS ver.16.0J (SPSS inc. Tokyo, Japan) was used.

\section{RESULTS}

\section{Cancer screening rate}

According to the report on regional health and elderly-health projects prepared in 2007 , the screening 
rates were : $11.8 \%$ for stomach cancer $; 18.8 \%$ for colorectal cancer; $18.8 \%$ for uterus cancer ; and $14.2 \%$ for breast cancer. Even the highest screening rate of lung cancer managed to reach only $21.6 \%$. The screening rate for stomach cancer gradually declined, and the variation rate was about $3 \%$ in both sexes. The screening rate for lung cancer has declined in the last 4 years with the variation rate of about $4 \%$. The screening rate for colorectal cancer has increased year by year with an annual increase rate of about $0.5 \%$. Its variation has been as great as about $8 \%$. The screening rate for uterus cancer experienced a declining trend from 1991, but it has increased 1.3 times higher in the last 3 years. The screening rate for breast cancer had a rapid increase in 2005, and has had an increasing trend overall (Figure 1).

On an international standard, Japan is at the lowest level among the 30 member countries of Organization for Economic Co-operation and Development (OECD), in comparison with the Western countries where the screening rates for breast cancer and

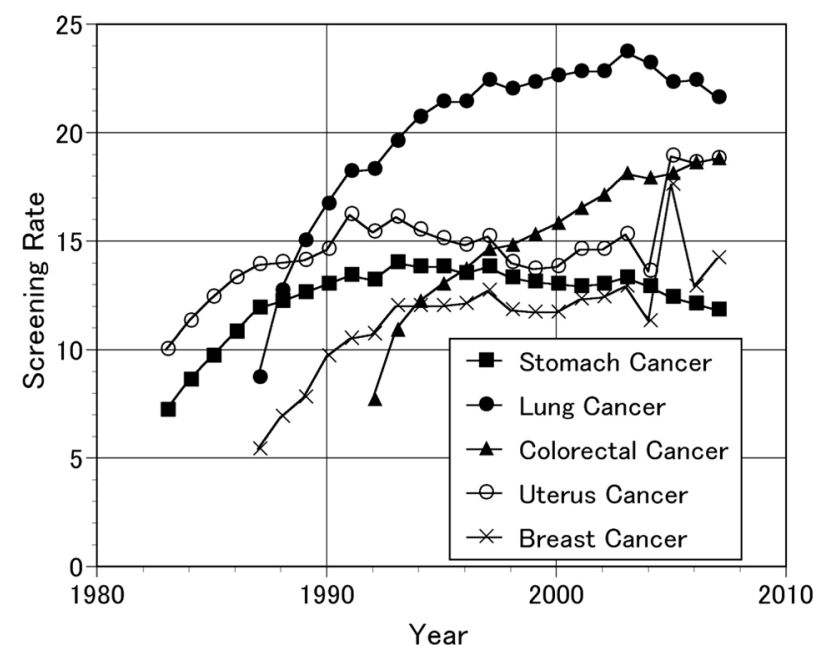

Figure 1. Trends in cancer screening rate uterus cancer are over $70 \%$, (Table 1) $(16,17)$.

\section{Cancer mortality rate}

The mortality rate for stomach cancer showed an increasing trend until around 1970s, but from then it showed a declining trend in the subsequent years. This variation approximated a value of 10 . According to gender, a declining tread was observed in women after 1970, while no change was observed in men after 1990, and the male mortality rate was 1.5 times greater than the female one. The mortality rate for stomach cancer in those aged 40 or over between 1970 and 1990 decreased year by year by the average of 3.7 people in men $(\mathrm{p}<0.001)$ and the average of 2.2 people in women $(\mathrm{p}<0.001)$ (Figure $2 \mathrm{~A})$. According to age groups, the higher age groups had a higher mortality rate both in women and men.

The mortality rate for lung cancer increased significantly year by year both in women and men, and its increase rate was the greatest compared with the other 4 cancers in all the years. Both in women and men, it increased 10 times higher in the last 50 years. Moreover, the increase in the mortality rate was significant for both women and men aged 40 or over : an increase of 2.5 people in one year for men $(\mathrm{p}<0.001)$ and an increase of 0.8 people for women $(p<0.001)$. The variation value in the mortality rate was : about 30 in men and about 20 in women, which showed a greater variation compared with that in the other cancers (Figure 2B). In the last 20 years, despite a declining trend in men aged over 65 or over, the mortality rates for both men and women tended to be higher as their ages were higher.

The mortality rate for colorectal cancer in both sexes increased a lot year by year in all the years. The variation value of the rate was about 15 . In the last 50 years, there were an about 7 times increase in men and an about 6 times increase in women.

Table 1. Screening rate (\%) of cervical and breast cancer

\begin{tabular}{|l|c|c|c|c|c|c|}
\hline \multirow{2}{*}{} & \multicolumn{2}{|c|}{ Cervical cancer screening of women aged 20-69 } & \multicolumn{3}{|c|}{ Mammography screening of women aged 50-69 } \\
\cline { 2 - 7 } & 2000 & 2003 & 2006 & 2000 & 2003 & 2006 \\
\hline Japan & 22.6 & 23.7 & 24.5 & 22.5 & 23.3 & 23.8 \\
\hline United States & 85.7 & 83.9 & 83.5 & 77.8 & 76.0 & 72.5 \\
\hline United Kingdom & 83.4 & 81.2 & 79.4 & 69.8 & 74.7 & 70.7 \\
\hline Norway & 70.3 & 72.5 & 75.6 & 79.2 & 75.6 & 76.7 \\
\hline $\begin{array}{l}\text { Average of 30 countries } \\
\text { in OECD }\end{array}$ & 62.3 & 63.8 & 64.0 & 58.3 & 61.6 & 62.2 \\
\hline
\end{tabular}


In the last 20 years, the mortality rate for men was 1.2 times higher than that for women. For those aged 40 or over, the mortality rate increased in both

A
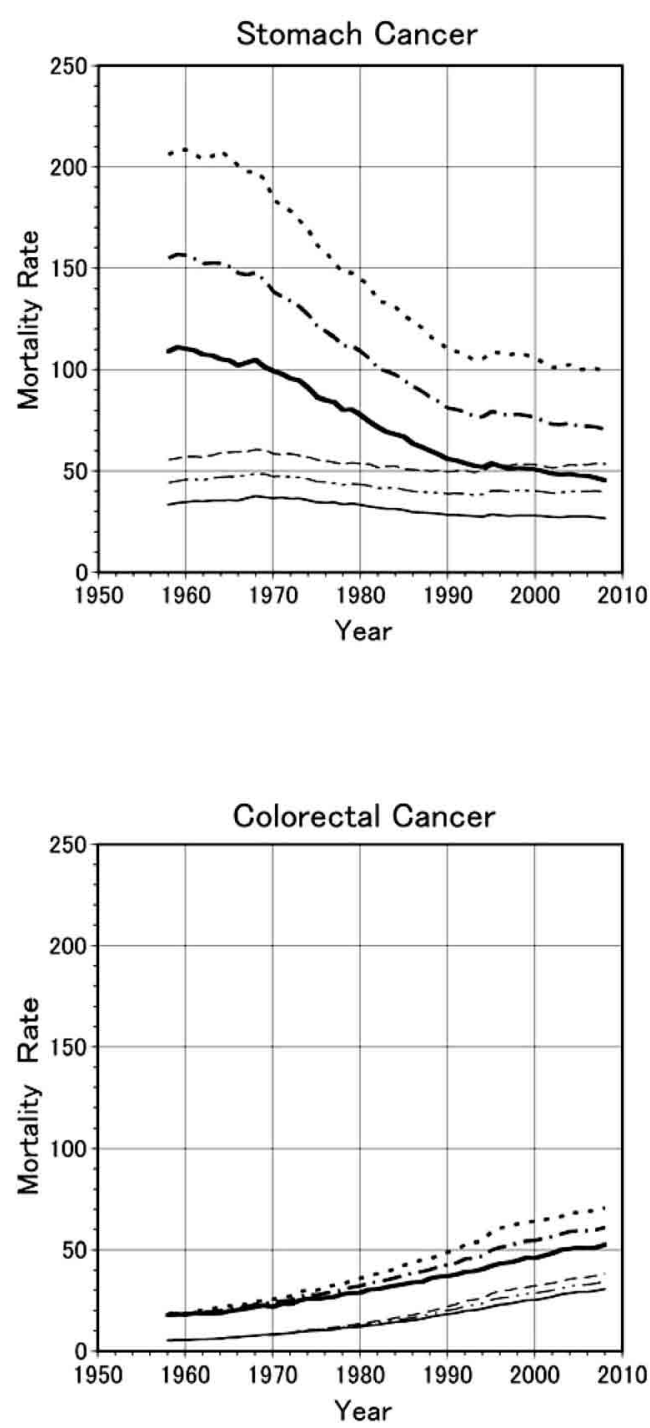

$\mathrm{D}$

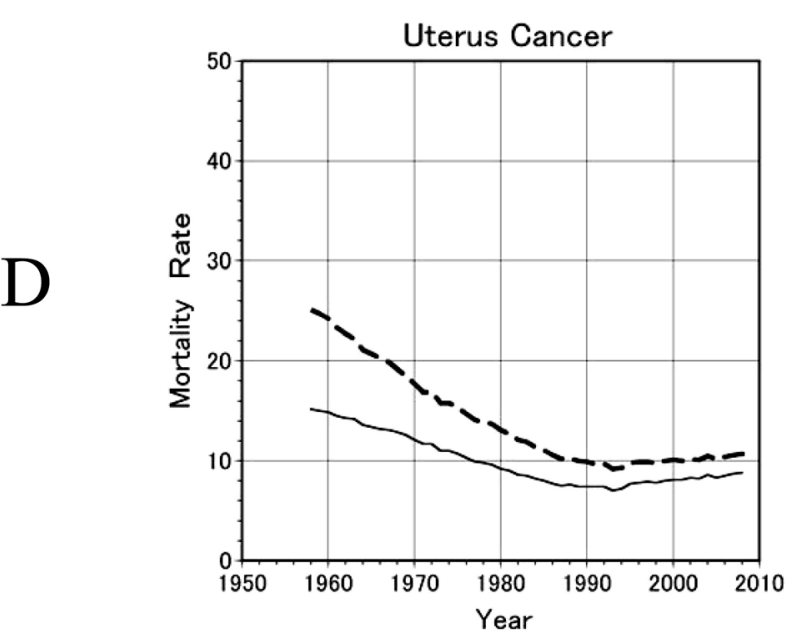

sexes : a 1.3 people increase in men in one year $(\mathrm{p}<$ $0.001)$ and 0.8 people increase in women $(\mathrm{p}<0.001)$ (Figure 2C). According to age groups, although the

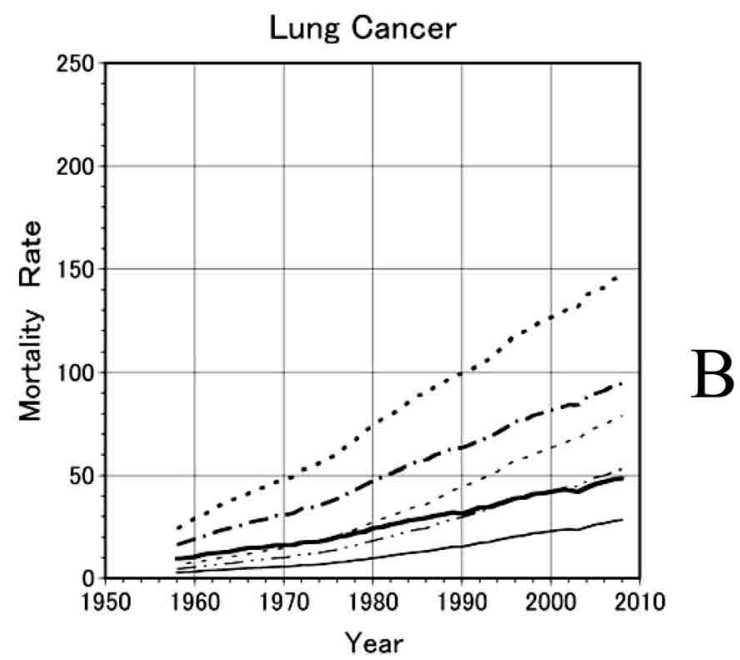

Figure 2. Trends in cancer mortality rate -- - - - - - - shows men and women aged 40 or over ........... shows men aged 40 or over shows women aged 40 or over

- - - - - - shows women aged 20 or over -........... shows all men and women shows all men shows all women

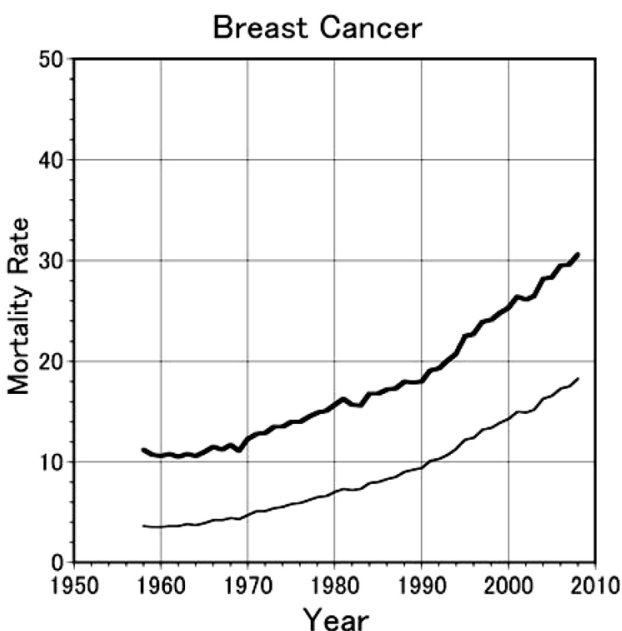


mortality rate became higher as the ages became higher, there was a declining trend in the rate for both sexes aged 55 years old or over in the last 10 years. This trend was more apparent in men than in women.

The mortality rate for uterus cancer declined until about 1990 but then tended to increase in the subsequent years. The rate was half as much as the rate 50 years ago. For those aged 20 years old or over, there was a 0.5 people decline in one year until about $1990(\mathrm{p}<0.001)$ but then a small annual increase of 0.08 people was observed $(\mathrm{p}<0.001)$ (Figure 2D).

The mortality rate for breast cancer has an increasing trend in all the years. For those aged 40 years old or over, there was an annual increase of 0.3 people in the period of 1970 to $1990(\mathrm{p}<0.001)$, and then the increase rate became higher by 0.7 people $(\mathrm{p}<0.001)$ (Figure 2E). According to age groups, there was an increasing trend in those aged 50 or over. Those aged younger than 50 have had a declining trend since 10 years ago (Figure 3 ).

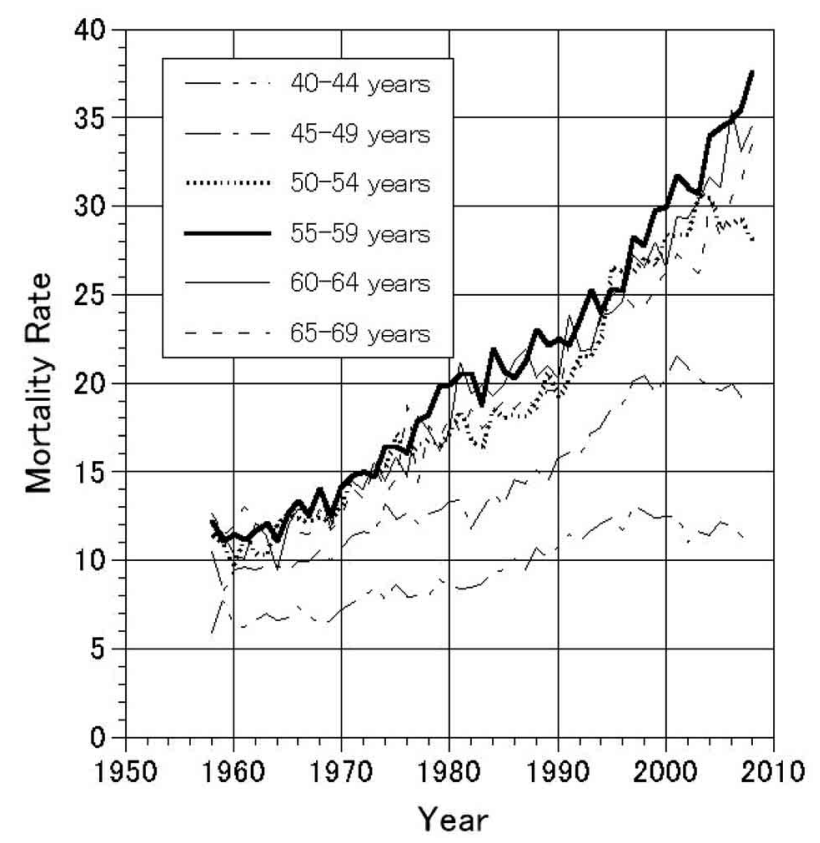

Figure 3. Trends in breast cancer mortality rate by age-group

\section{Relation between the cancer screening rate and the cancer mortality rate}

The relations between each screening rate for stomach cancer, lung cancer, colorectal cancer, uterus cancer, breast cancer and their respective mortality rate were illustrated in Table 2 . In stomach and colorectal cancers, there was a positive correlation between their screening rate and mortality rate $(p<0.001)$. Especially in colorectal cancer, a positive correlation was observed in both sexes $(p<$ 0.001 ). There was no significant statistical relationship between the screening rate for lung cancer and its mortality rate. There was no clear relation found between the screening rates for breast and uterus cancers and their mortality rates.

\section{Relation between cancer mortality rate and can- cer screening rate in administrative divisions}

The screening rate for stomach cancer was 19\% to $50 \%$, and differed greatly among regions. The national average of the rate was $27 \%$ and $34 \%$ for women and men respectively, and the male rate was significantly higher than the female one $(p<0.001)$. The mortality rate of stomach cancer was $7 \%$ and $18 \%$ for women and men respectively. The relation between the screening rate and the mortality rate of stomach cancer was not significant (Figure 4A).

The screening rate of lung cancer had twice or more a regional difference, and it was $14 \%$ to $37 \%$. The national average of the screening rate was $23 \%$ and $27 \%$ for women and men respectively, and the value was lower than the stomach cancer screening rate. In relations with the screening and the mortality rate of lung cancer, the mortality rate significantly decreased as the screening rate improved $(p<0.005)$. In other words, the mortality rate decreased by 0.12 when the screening rate improved $1 \%(p<0.05)$. In the aspect of gender, the result had a similar tendency $(\mathrm{p}<0.05)$ (Figure $4 \mathrm{~B})$.

The screening rate of colorectal cancer was $16 \%$ to $38 \%$, and the regional difference was great. The

Table 2. Correlation between screening rate (\%) and mortality rate for each cancer

\begin{tabular}{|l|c|c|c|c|c|c|c|c|c|c|c|}
\hline \multirow{2}{*}{} & \multicolumn{3}{|c|}{ Stomach cancer } & \multicolumn{3}{c|}{ Lung cancer } & \multicolumn{3}{c|}{ Colorectal cancer } & $\begin{array}{c}\text { Uterus } \\
\text { cancer }\end{array}$ & $\begin{array}{c}\text { Breast } \\
\text { cancer }\end{array}$ \\
\cline { 2 - 14 } & All & Men & Women & All & Men & Women & All & Men & Women & Women & Women \\
\hline Correlation coefficient & $0.833^{\star}$ & 0.706 & $0.862^{\star}$ & 0.643 & 0.652 & 0.621 & $0.992^{\star}$ & $0.982^{\star}$ & $0.991^{*}$ & 0.260 & 0.461 \\
\hline Regression slope & $3.60^{\star}$ & 3.11 & $3.34^{*}$ & 4.67 & 6.68 & 2.59 & $1.78^{\star}$ & $1.80^{\star}$ & $1.76^{\star}$ & 0.06 & 0.885 \\
\hline
\end{tabular}

${ }^{*} \mathrm{p}<0.001$

Mortality rate is calculated as (Cancer Deaths/Population) $\times 100,000$

The center for cancer control and information services, National cancer center (5) 
national average of the screening rate was $23 \%$ and $28 \%$ for women and men respectively, and the result was similar to that of lung cancer (Figure 4C).

The screening rate of uterus cancer was $17 \%$ to $31 \%$, and the national average of the rate was $22 \%$. The result had a similar trend to that of breast

A
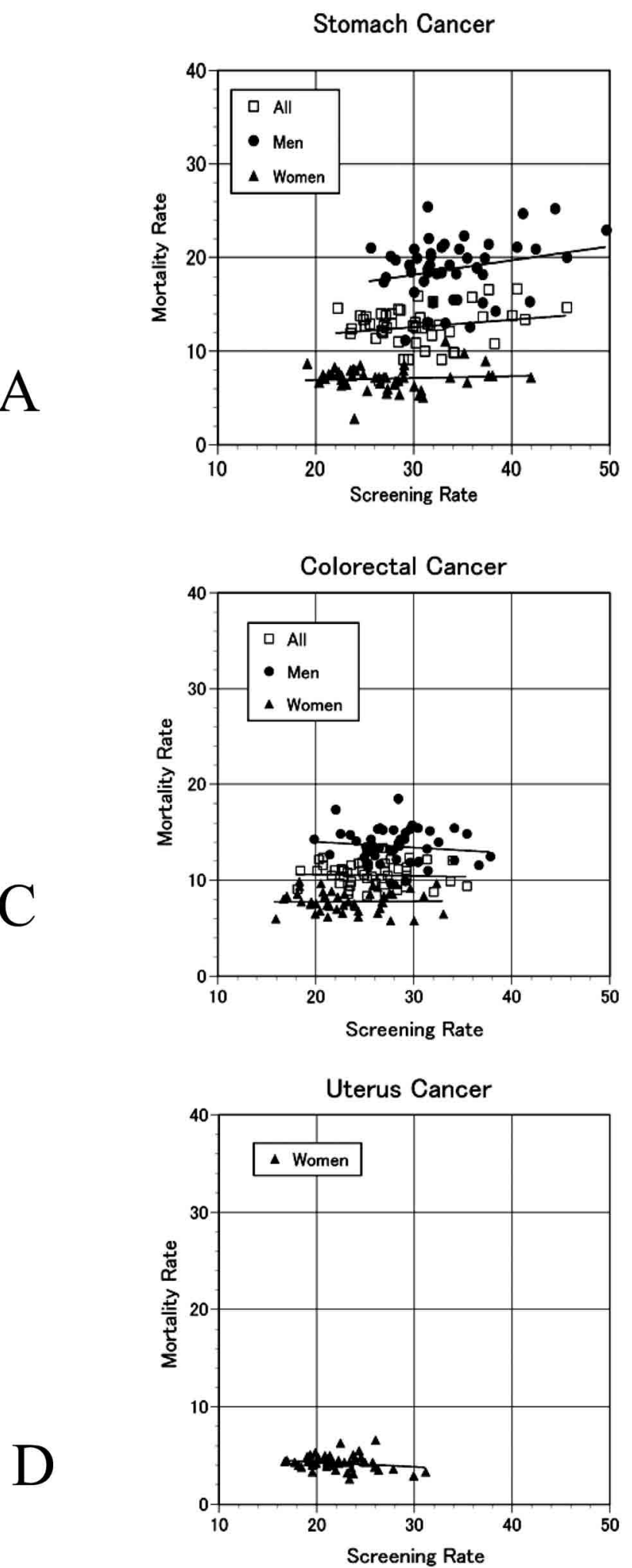

cancer (Figure 4D).

The screening rate of breast cancer was $14 \%$ to $33 \%$, and the national average of the rate was $21 \%$. The results were moderately low, compared with stomach cancer, lung cancer and colorectal cancer (Figure 4E) (Table 3). A significant positive

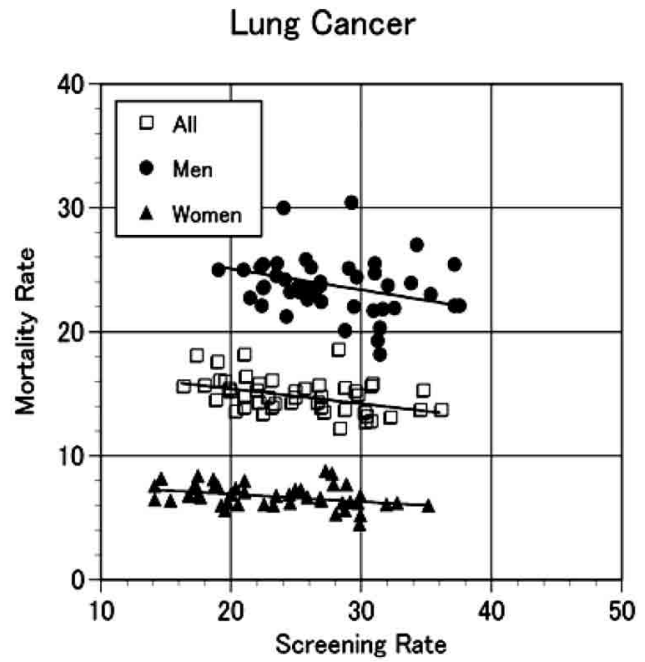

B

Figure 4.

Relationship between the screening rate and the mortality rate for cancer in prefectures

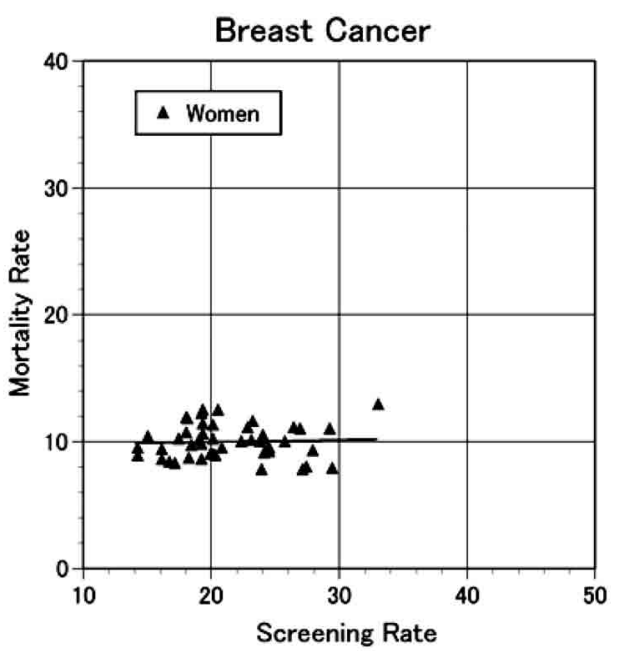


Table 3. Correlation between screening rate (\%) and mortality rate for cancer in prefectures

\begin{tabular}{|c|c|c|c|c|c|c|c|c|c|}
\hline & \multicolumn{3}{|c|}{ Stomach cancer } & \multicolumn{3}{c|}{ Lung cancer } & \multicolumn{3}{c|}{ Colorectal cancer } \\
\cline { 2 - 9 } & All & Men & Women & All & Men & Women & All & Men & Women \\
\hline $\begin{array}{c}\text { Correlation } \\
\text { coefficient }\end{array}$ & 0.201 & 0.241 & 0.084 & $0.424^{\star *}$ & $0.323^{\star}$ & $0.361^{*}$ & 0.051 & 0.128 & 0.017 \\
\hline $\begin{array}{c}\text { Regression } \\
\text { slope }\end{array}$ & -0.08 & 0.15 & -0.02 & $-0.12^{\star *}$ & $-0.17^{\star}$ & $-0.06^{*}$ & -0.02 & -0.06 & 0.005 \\
\hline
\end{tabular}

\begin{tabular}{|c|c|c|}
\hline & Uterus cancer & Breast cancer \\
\cline { 2 - 3 } & Women & Women \\
\hline $\begin{array}{c}\text { Correlation } \\
\text { coefficient }\end{array}$ & 0.198 & 0.053 \\
\hline Regression slope & -0.05 & 0.02 \\
\hline
\end{tabular}

${ }^{*} \mathrm{p}<0.05,{ }^{* *} \mathrm{p}<0.005$

mortality rate shows age-adjusted cancer death rate.

The center for cancer control and information services, National cancer center (5)

correlation was found between the breast cancer screening rate and the uterus cancer screening rate $(r=0.932, p<0.001)$.

\section{DISCUSSION}

In the lung cancer screening cancer rate, we found that the mortality rate decreased with the improvement in the cancer screening rate. This means that cancer screening examination helps cancer mortality decrease.

In this consideration of the relation between the cancer screening rate and the mortality rate, the important point to pay attention to was the result that a statistically positive correlation was found in the cases of colorectal cancer and stomach cancer in women, and that the mortality rate increased as the cancer screening rate was improved. However, the result of this research was not a cohort study but an observation of the correlations between the cancer screening rate and the mortality rate in each year. In this research, although the subject ages were identified, the mortality rate was not calculated from the death number of the screening recipients. Consequently, we treated the results as an information material to analogize with problems in cancer screening, and our consideration on is as below.

For colorectal cancer, whose screening rate has increased recently, the faecal occult blood test is recognized worldwide as a method of screening and as having an effect of decreasing the mortality rate (18). However, in the screening situation of colorectal cancer in Japan, problems such as the inadequate implementation structure of workup have been pointed out (19). Hence, we thought that the screening of colorectal cancer has not achieved early detection of it.

On lung cancer, there are reports from results of cohort studies in Japan that the mortality rate for screening recipients is lower than that for nonrecipients $(20,21)$. However, on the screening methods, chest radiography and sputum cytology have only limited effect in decreasing the mortality rate. Though the low-dose thoracic CT screening is recommended, its efficacy has not been reported as established (22). Thus, the improvement in the accuracy of screening is considered to be an issue. Reduction in the mortality rate is a pressing issue with lung cancer which requires to be solved through the improvement in the accuracy of and in the rate of screening as well as the promotion activities such as advising on smoking.

On breast cancer, although its occurrence has increased in European and North American countries, the mortality rate lowered $(23,24)$. On the other hand, its occurrence and mortality rate has increased year by year in Japan. It was considered that no effective screening program against breast cancer had been introduced (25).

The mammography screening rate is $70 \%$ to $80 \%$ in the West, whereas in Japan it is only $12.4 \%$ of the targeted women aged 40 or over (26). On this matter, Japan is at the lowest level among the 30 member countries of OECD. Despite a high screening rate in Europe, the European Council recommended the implementation of the screening for breast and cervical cancers for women and the screening for colorectal cancer for both women and 
men, thus further encouraging cancer screening in the European Union (27). In the results of this research, an increase in the mortality rate for breast cancer was observed among the age groups aged 50 or over, but conversely there was a decline in the younger age groups. From this, it is considered necessary at least for women aged 50 or over to undertake cancer screening routinely.

Next, though the mortality rate for uterus cancer dropped until 1990, there has been an increasing trend since then. As reasons for this, the increase of cervical cancer among young people and the current screening solely based on cytology are pointed out (28). However, as organized screening is reported to lead decline in the morbidity and mortality rate in the Nordic countries (29), clear effects can be expected in organized screening targeting a group. There is also a reported case in which the screening for cervical cancer for those aged between 30 to 79 years old would decline the mortality rate (21). In our research, the mortality rate for uterus cancer, which showed a declining trend, has indicated an increasing trend since 1990s though the trend has been gradual. In the prevention of more increase, measures to improve the screening rate for young people are a high priority. Since 2009, for the purpose of disseminating and promoting the screening for female-specific cancers, early detection of cancer, and appropriate awareness of health, a handbook for the screening for uterus and cervical cancers and coupons for free screening have been distributed to women at a certain age. It is hoped that this will help the screening rate rise close to the one in Western countries in future (30).

From the view of screening recipients, their concerns include those about the screening environment and screening methods. In fact, the screening rates in urban areas are below the nationwide averages $(12,31)$. On uterus cancer, which is femalespecific, factors such as the sense of shame are recognized as causing a decline in the screening rate. Recently, the number of medical institutions for women has increased as the demand for medical treatment with gender consideration is high (32). Thus, such institutions should be made full use of.

\section{CONCLUSION}

A statistical analysis was conducted on the cancer screening rate (between the year 1983 and 2007) and the cancer mortality rate (between 1958 and 2008) based on the information obtained from databases and publications. As a result, in the lung cancer screening cancer rate, we found that the mortality rate decreased with the improvement of the cancer screening rate. This means that cancer screening examination helps mortality decrease. Therefore, for lung cancer which has a high mortality rate with an increasing trend, breast cancer whose mortality rate continues to rise in people aged 50 or over, and uterus cancer whose mortality rate used to have a declining trend but now has an increasing trend, it is considered essential to take some immediate measures.

\section{REFERENCES}

1. Ministry of Health, Labour and Welfare, Summary of Vital Statistics, (http : //www.mhlw.go. $\mathrm{jp} /$ english/database/db-hw/populate/index. html)

2. Japanese Foundation for Cancer Research (http : //www.jfcr.or.jp/english/about/index. html)

3. The Japan Cancer Society (http://www. jcancer.jp)

4. Moore MA, Sobue T: Cancer research and control activities in Japan : contributions to international efforts. Asian Pac J Cancer Prev 10 : 183-200, 2009

5. The center for cancer control and information services, National cancer center : History of cancer control in Japan, Cancer statistics in Japan and Cancer mortality (1958-2008) (http:// ganjoho.ncc.go.jp/professional/statistics / statistics.html)

6. Mizoue T, Yoshimura T, Tokui N, Hoshiyama Y, Yatsuya H, Sakata K, Kondo T, Kikuchi S, Toyoshima H, Hayakawa N, Tamakoshi A, Ohno Y, Fujino Y, Kaneko S, Japan Collaborative Cohort Study Group : Prospective study of screening for stomach cancer in Japan. Int J Cancer 106 : 103-107, 2003

7. Ito $\mathrm{Y}$, Ohno Y, Rachet B, Coleman MP, Tsukuma $\mathrm{H}$, Oshima A : A cancer survival trends in Osaka. Jpn J Cli Oncol 37 : 452-458, 2007

8. Medical information network distribution service (Minds), Japan Council for Quality Health Care : Guideline of colorectal cancer screening in 2005, stomach cancer screening in 2006 and lung cancer screening, 2006 (in Japanese) 
9. Hamashima C, Shibuya D, Yamazaki H, Inoue K, Fukao A, Saito H, Sobue T: The Japanese guidelines for gastric cancer screening, Jpn J Clin Oncol 38 : 259-267, 2008

10. Saito H, Aoki A : A strategy to reduce cancer mortality through early detection. Japan J Cancer Clin 52: 595-600, 2006

11. Hamashima $\mathrm{C}$, Sobue $\mathrm{T}$ : Issues and perspective on cancer screening program. clinic All-Round (Sougo Rinsho) 55 : 1416-1422, 2006 (in Japanese)

12. Ministry of Health, Labour and Welfare : Summary of report on regional health services and health services for the elderly

13. Journal of health and welfare statistics, Health and welfare statistics association, Tokyo, 19802009

14. Foundation for promotion of cancer research : Cancer statistics in Japan(http : //www.fpcr.or. jp/publication/statistics.html

15. Cabinet Office : SNA statistics (http : //www. esri.cao.go.jp/en/sna/data.html)

16. Screening, survival and mortality for cervical cancer: OECD iLibrary, Health at a glance 2009 : OECD indicators, 2009 (http : //www. oecdilibrary.org)

17. Screening, survival and mortality for breast cancer: OECD iLibrary, Health at a glance 2009 : OECD indicators, 2009 (http : //www. oecdilibrary.org)

18. Towler B, Irwig L, Glasziou P, Kewenter J, Weller D, Silagy C : A systematic review of the effects of screening for colorectal cancer using the faecal occult blood test, hemoccult. BMJ 29 : 559-65, 1998

19. Sobue T, Hamashima C, Saito H, Shimada T, Matsuda K, Nishida H : Development of guidline for colorectal cancer mass screening. Jpn J Cancer Chemother 32:961-915, 2006 (in Japanese)

20. Lee KJ, Inoue M, Otani T, Iwasaki M, Sasazuki S, Tsugane S, JPHC Study Group : Gastric cancer screening and subsequent risk of gastric cancer : a large-scale population-based cohort study, with a 13-year follow-up in Japan. Int J Cancer 118 : 2315-2321, 2006

21. Aklimunnessa K, Mori M, Khan MM, Sakauchi F, Kubo T, Fujino Y, Suzuki S, Tokudome S, Tamakoshi A, JACC Study Group : Effectiveness of cervical cancer screening over cervical cancer mortality among Japanese women. Jpn J Clin Oncol 36 : 511-518, 2006

22. Sagawa M, Usuda K, Aikawa H, Machida Y, TanakaM, Ueno M, Sakuma T : Lung cancer screening and its efficacy. Gen Thorac Cardiovasc Surg 57 : 519-527, 2009

23. SEER Cancer Statistics Review 1975-2006, National Cancer Institute (http : //seer.cancer. gov/csr/1975_2006/index.html)

24. Karim-Kos HE, de Vries E, Soerjomataram I, Lemmens V, Siesling S, Coebergh JW : Recent trends of cancer in Europe : a combined approach of incidence, survival and mortality for 17 cancer sites since the 1990s. Eur J Cancer $44: 1345-1389,2008$

25. Ito $\mathrm{Y}$, Ioka A, Tanaka M, Nakayama T, Tsukuma $\mathrm{H}$ : Trends in cancer incidence and mortality in Osaka, Japan : Evaluation of cancer control activities. Cancer Sci $100: 2390-2395$, 2009

26. Morimoto T, Nagao T, Okazaki K, Kira M, Nakagawa Y, Tangoku A : Current status of breast cancer screening in the world. Brest Cancer $16: 2-9,2009$

27. The Council of the European Union : Council recommendation of 2 December on cancer screening. Off J Eur Union 878 : 34-38, 2003

28. Matsuura Y, Kawagoe T, Toki N, Hachisuga T, Kashimura M : Uterine cervical cancer screening in Japan : today and future. J UOEH 31 : 181-193, 2009 (in Japanese)

29. Arbyn M, Raifu AO, Autier P, Ferlay J : Burden of cervical cancer in Europe : estimates for 2004. Ann Oncol 18 : 1708-1715, 2007

30. Office for Cancer Control, Health Services Bureau, Ministry of Health, Labour and Welfare (http : //ganjoho.ncc.go.jp/public/statistics/ backnumber/1isaao000000068m-att/cancer_ control.pdf )

31. Katoh K, kanno S : Factors Associated with Cancer Screenings Participation Rates : Results from Tadami Town Health Survey 2003. Bulletin of Fukushima School of Nursing $11: 29$ 37, 2009 (in Japanese)

32. Sasaki A, Namizaki Y, Yamada S, Tanabe M : A Study of Influencing Factors on Breast and Cervical Cancer Screening Behavior, and Effect of a Health Educational Program on Menopausal Women. Journal of interdisciplinary research $7:$ 15-28, 2006 (in Japanese) 